\title{
perifèria
}

Número 16, junio 2012

revistes.uab.cat/periferia - www.periferia.name

\section{Reflexões sobre a qualidade da educação brasileira: desafios do nosso tempo histórico}

\author{
Adelar João Pizetta ${ }^{1}$
}

\begin{abstract}
Resumen
Este artigo tem por finalidade refletir sobre alguns aspectos da realidade educacional brasileira, problematizando a questão da qualidade da educação em relação à quantidade. Para isto, parte de dados do Censo da Educação Superior de 2009 do Instituto Nacional de Estudos e Pesquisas Educacionais (INEP), da Pesquisa Nacional por Amostra de Domicílios do Instituto Brasileiro de Geografia e Estatística (IBGE) de 2009 e da Pesquisa de Avaliação da Qualidade dos Assentamentos de Reforma Agrária no Brasil, realizada pelo INCRA em 2010. Busca demonstrar a relação entre os aspectos econômicos e educacionais como heranças de um modelo de desenvolvimento desigual e combinado. Demonstra que a concentração da riqueza e da terra, por um lado, e a exclusão de ampla maioria da população trabalhadora pobre, por outro, conformam os dois lados da mesma moeda. Por último, pretende instigar a busca coletiva de alternativas para superar essa cicatriz histórica, por intermédio da construção de um novo projeto societário, emancipatório, em que a educação passe a cumprir seu real e relevante papel de fomentadora da vivência de novos valores.
\end{abstract}

Palavras-chave: economia, educação, movimento social, quantidade/qualidade.

\begin{abstract}
Reflecting on Brazilian education quality: the challenges of our historic time.

This article aims at considering some aspects of Brazilian educational reality, questioning the educational quality matters related to quantity. To do so, it begins with data from Censo da Educação Superior de 2009 (College Education Census of 2009 ) by Instituto Nacional de Estudos e Pesquisas Educacionais (INEP - National Study and Research Institute), and the National Research by Home Samples conducted by Instituto Brasileiro de Geografia e Estatística (IBGE) in 2009, and the Evaluation of Quality at Land Reform Camps in Brazil - carried out by INCRA in 2010 - will be used. It tries to show the relationship between the economical and educational aspects as 'heritage' of an unequal and combined development model. The wealth and land concentration, on one hand, and the exclusion of a noticeable majority of working poor population, on the other hand, comprise the two sides of the same coin. Finally, it intends to support the collective search for alternatives for this historical 'scar', by means of building a new society emancipator project, on which education will play its real and relevant role of inciting new values living.
\end{abstract}

Keywords: economy, education, social movement, quantity / quality.

\footnotetext{
${ }^{1}$ Doutorando em Educação do Programa de Pós-Graduação em Educação da Universidade Federal do Espírito Santo - PPGE/UFES e, Bolsista da CAPES. Email: ajpizetta@enff.org.br
} 


\section{perifèria \\ Número 16, junio 2012 \\ revistes.uab.cat/periferia - www.periferia.name}

\section{Introdução}

A história não está presa a cadeias. E a função da atividade política dos trabalhadores se volta, exatamente, no sentido de quebrar as cadeias que tentam converter a história da humanidade numa história natural da burguesia (Florestan Fernandes).

Este artigo tem por objetivo problematizar a relação quantidade-qualidade na educação brasileira a partir de dados do Censo da Educação Superior de 2009 do Instituto Nacional de Estudos e Pesquisas Educacionais (INEP) ${ }^{2}$, da Pesquisa Nacional por Amostra de Domicílios, do Instituto Brasileiro de Geografia e Estatística (IBGE) ${ }^{3}$ de 2009 e da Pesquisa de Avaliação da Qualidade dos Assentamentos de Reforma Agrária no Brasil, realizada pelo Instituto Nacional de Colonização e Reforma Agrária (INCRA) ${ }^{4}$ em 2010.

A relevância do tema está centrada na compreensão, das feridas abertas na nossa formação histórica, que mantêm praticamente inalteradas as linhas centrais de um modelo hegemônico de desenvolvimento no qual o humano foi subordinado à mercantilização da vida e do trabalho. Esse é um dado estrutural que se mantém apesar das políticas educacionais executadas nos últimos anos.

A nossa realidade histórica requer uma tomada de posição dos profissionais da educação, dos estudantes, dos movimentos sociais e da sociedade como um todo para, coletivamente, revelar a oculta e, ao mesmo tempo manifesta realidade

\footnotetext{
2 O Instituto Nacional de Estudos e Pesquisa (INEP), fundado em 1984, tem como objectivos principais promover os estudos e pesquisas no domínio das ciências sociais e naturais relacionados com os problemas de desenvolvimento do país e contribuir para a valorização dos recursos humanos locais. A atividade principal do INEP consiste na realização de investigação fundamental e na elaboração de estudos, sendo constituído por um corpo de investigadores nacionais permanentes e uma rede de investigadores associados nacionais e estrangeiros.

3 O Instituto Brasileiro de Geografia e Estatística (IBGE) é uma fundação pública da administração federal brasileira criada em 1934 e instalada em 1936 com o nome de Instituto Nacional de Estatística. O nome atual data de 1938. A sede do IBGE está localizada na cidade do Rio de Janeiro. O IBGE tem atribuições ligadas às geociências e estatísticas sociais, demográficas e econômicas, o que inclui realizar censos e organizar as informações obtidas nesses censos, para suprir órgãos das esferas governamentais federal, estadual e municipal, e para outras instituições e o público em geral.

4 O Instituto Nacional de Colonização e Reforma Agrária (INCRA) é uma autarquia federal da Administração Pública brasileira. O INCRA administra a questão agrária no Brasil. Sua sede é no Edifício Palácio do Desenvolvimento no município de Brasília, Distrito Federal.
} 


\section{perifèria \\ Número 16, junio 2012 \\ revistes.uab.cat/periferia - www.periferia.name}

desigual da educação pública brasileira, para um posterior enfrentamento dessa mesma realidade sócio-educacional dramática, no sentido de alterá-la.

Do contrário, corremos o risco de seguir na perspectiva da práxis alienadora de naturalizar uma problemática histórica em que a educação foi transformada em privilégio de alguns poucos, frente à não execução de políticas públicas includentes e de qualidade para milhões de jovens e adolescentes pobres, residentes em vários territórios brasileiros, do campo e da cidade.

Em pleno século XXI, essa grande era dos maiores resultados das revoluções técnico-científicas que encurtaram o tempo e aproximaram espaços longínquos, o Brasil se apresenta ao mundo como uma das primeiras economias em produção, combinada com uma péssima distribuição da riqueza gerada: os $10 \%$ mais ricos da população se apropriam de $75 \%$ da riqueza social produzida, enquanto na outra ponta, os $90 \%$ mais pobres repartem entre si os parcos $25 \%$ restantes ${ }^{5}$.

Esse é apenas um dos paradoxos do desenvolvimento desigual e combinado ${ }^{6}$ brasileiro: estamos, ao mesmo tempo, entre as oito economias mais ricas e mais desiguais do mundo.

Segundo Pochmann (2007), o Brasil transfere anualmente, desde os anos 90 , de 5 a $8 \%$ de todo o Produto Interno Bruto (PIB) para os ricos, enquanto apenas $0,5 \%$ do PIB nacional chegam aos brasileiros que vivem em condições de extrema pobreza e perfazem uma média de 10 milhões de famílias.

No que tange à questão da fome e da concentração da terra, Stédile (2011) destaca que, segundo dados do Instituto de Pesquisa Econômica Aplicada (IPEA), de 1993, havia no Brasil 32 milhões de pessoas passando fome e 65 milhões de pessoas mal alimentadas. Isto explicita a pertinente tese de Josué de Castro (2007)

\footnotetext{
${ }^{5}$ Atlas da Exclusão Social: os ricos no Brasil, volume 3, São Paulo: Cortez, 2004.

3 Florestan Fernandes, relata, em seu livro Capitalismo dependente e classes sociais na América Latina (2009 [1973]) que, neste continente, o desenvolvimento se deu a partir das necessidades do modo geral de produção capitalista em expansão no mundo, o que traz para América Latina um papel de ser o fornecedor dos principais elementos constitutivos do avanço do capitalismo das economias centrais. Por isto, o desenvolvimento da periferia é dependente e subordinado à lógica geral de acumulação, cujo centro gravitacional é o capital mais avançado que, em cada época histórica, requer utilizar de artimanhas particulares para suas históricas formas de manipulação da ordem a seu favor: colonialismo, (in)dependência, neoliberalismo.
} 


\section{perifèria \\ Número 16, junio 2012 \\ revistes.uab.cat/periferia - www.periferia.name}

sobre a geografia da fome no Brasil, quando retrata que existem dois grupos fruto do modelo de desenvolvimento desigual e combinado: de um lado os que não comem e, do outro lado, os que não dormem com medo dos que não comem.

Em relação à posse da terra, observa-se a continuidade do fenômeno da concentração, pois as propriedades acima de 1.000 hectares representam 1,6\% dos imóveis e controlam $43,8 \%$ de toda a terra agricultável, enquanto as pequenas propriedades, de até 25 hectares, representam 57,6\% dos imóveis, e, somam juntas, apenas $6,3 \%$ da área total ${ }^{7}$. Essa realidade coloca o Brasil entre os países que mais concentram a terra, produzindo altos índices de miséria, de violência e de analfabetismo.

A referência a esses dados demonstra a forte relação de interdependência estabelecida entre indicadores econômicos e educacionais (veremos mais adiante), dois lados de uma mesma moeda. Ou seja, são partes constituintes de um modelo de desenvolvimento historicamente implantado, que concentra e exclui, instituindo um modelo de educação pertinente com sua lógica de dominação.

Esse fenômeno fica evidente em Fernandes (1989:132-3) quando, ao interpretar os dilemas e problemas sociais brasileiros, chama a atenção para a relação direta existente entre a miséria e o baixo nível cultural, de escolarização e de formação das camadas populares.

Esses problemas e dilemas sociais dizem respeito à miséria (relativa e absoluta), à fome, aos milhões de desempregados, à habitação, à extrema concentração da propriedade agrária, às migrações [...] à reforma agrária, à reforma urbana, à saúde, ao abandono do menor [...] As tentativas de solução de todos esses problemas e dilemas esbarram no baixo padrão educacional das massas e do nível de consciência de classe dos trabalhadores.

Assim, o baixo nível de conhecimento e de consciência das classes trabalhadoras da, mesma forma que a fome e a miséria, também as desapropriam do acesso às

\footnotetext{
7 Instituto Nacional de Colonização e Reforma Agrária (INCRA). II Plano Nacional de Reforma Agrária (PNRA). Brasília: Ministério do Desenvolvimento Agrário, 2004.
} 


\section{perifèria \\ Número 16, junio 2012 \\ revistes.uab.cat/periferia - www.periferia.name}

políticas públicas que Ihes possibilitaria um nível de conhecimento crítico necessário para uma tomada de consciência sobre sua atual, mas não eterna, condição de sujeito subordinado ao poder do capital, dificultando a ação de resistência e de luta pela transformação social da realidade.

Recai, portanto, sobre a totalidade da vida social a complexidade e profundidade dessa herança histórica de dominação na qual o sistema educacional brasileiro temse configurado como um vetor central do desenvolvimento desigual e combinado. Vale destacar que, até a primeira década deste século, apesar das estatísticas terem melhorado, a problemática ainda não foi encarada com a necessária e merecida seriedade, como veremos mais adiante.

Para corroborar a reflexão proposta, o texto foi estruturado em duas partes seguidas das considerações finais. Em primeiro lugar, será problematizada a relação dialética entre quantidade/qualidade, com destaque para alguns indicadores da realidade educacional brasileira. Logo após, será preciso refletir sobre alguns dados da temática educacional do campo, destacando as fraturas que continuam existindo apesar das políticas implantadas nos últimos anos. Por fim, serão levantadas algumas reflexões sobre o sentido do termo qualidade como demanda de práticas de resistência e lutas atuais.

\section{Indicadores da realidade educacional: 0 analfabetismo e a educação superior}

Ao observar os dados da educação brasileira recente, na sua relação quantidade/qualidade, fornecidos pela Pesquisa Nacional por Amostra de Domicílios $(P N A D)^{8}$, do Instituto Brasileiro de Geografia e Estatística (IBGE) 2009, e do Censo Escolar do INEP/MEC ${ }^{9}$ (2002 a 2009), a conclusão não é nada animadora.

\footnotetext{
${ }^{8}$ A Pesquisa Nacional por Amostra de Domicílios (PNAD) investiga anualmente, de forma permanente, características gerais da população, de educação, trabalho, rendimento e habitação e outras, com periodicidade variável, de acordo com as necessidades de informação para o País, como as características sobre migração, fecundidade, nupcialidade, saúde, segurança alimentar, entre outros temas.

${ }^{9}$ O Ministério da Educação (MEC), é um órgão do Governo Federal, fundado em 1930.
} 


\section{perifèria \\ Número 16, junio 2012 \\ revistes.uab.cat/periferia - www.periferia.name}

O Brasil possui 14,1 milhões de analfabetos, o que corresponde a 9,7\% do total da população com 15 anos ou mais de idade, sendo que, no nordeste, o índice chega a $18,7 \%$ da população! Os analfabetos funcionais, isto é, aqueles brasileiros considerados aptos para a leitura e para a escrita, mas inaptos para a compreensão do texto lido e/ou escrito, somam sete milhões de pessoas! Assim, somando os dois grupos, chegamos a uma cifra de mais de 21 milhões de analfabetos!

No outro extremo da pirâmide educacional, constatamos que, na educação superior, $10,6 \%$ das instituições são públicas (245), enquanto $89,4 \%$ das instituições são privadas (2.069), segundo os dados do Censo do Ensino Superior de 2009. No total de estabelecimentos tem 186 universidades, 127 centros universitários, 1966 faculdades e apenas 35 Institutos Federais (IFs).

De acordo com Araújo (2011), segundo dados da Síntese de Indicadores Sociais, divulgado pelo IBGE em outubro de 2009, somente 3\% dos jovens entre 18 e 24 anos de idade ingressam nas Universidades Públicas. Se somados às matrículas em Instituições Privadas, o percentual sobe para apenas $13,9 \%$ da população, o que não significa que concluirão os cursos. Ou seja, mais de $85 \%$ dos jovens não ingressam nos cursos superiores, o que coloca o Brasil, neste item, em último lugar dentre as 30 maiores economias do mundo. No entanto, projetos como o Programa Universidade para Todos (ProUni) - uma espécie de subsídio público para a mercantilização da educação ${ }^{10}$; do Programa de criação de novas vagas nas universidades públicas (Reuni) e da nova Lei de Inovação Tecnológica estabelecem parcerias público-privado - tentam redimensionar as universidades, mas só conseguem reconfirmar a histórica orientação burguesa, elitista, privatista e conservadora de nosso ensino superior, assim exposta pelo Professor Leher (2010:380):

\footnotetext{
10 Segundo o professor Leher (2010:382) é um programa de compra de vagas nas instituições privadas por meio da pior forma de uso das verbas públicas, as isenções tributárias, justo a mais opaca ao controle social.
} 


\section{perifèria}

Número 16, junio 2012

revistes.uab.cat/periferia - www.periferia.name

Também na educação superior a aliança com os representantes do capital se verifica como axial. Não apenas a camada burguesia de serviços se beneficia dessa aliança, mas outras frações relacionadas com as indústrias e com as commodities igualmente têm relevante influência na definição do modelo de ciência e tecnologia do país, como é possível depreender da análise da Lei de Inovação Tecnológica e legislação afim.

Outro aspecto relevante a destacar é o crescimento significativo dos cursos de educação a distância (EaD). Enquanto os cursos presenciais tiveram um crescimento de $12,5 \%$ os de EaD tiveram um aumento de 30,4\%, de 2008 para 2009. Essa evolução também é acompanhada pelo aumento no número de matriculas nos cursos de EaD, que, em 2009, atingiram a cifra de $14,1 \%$ do total das matrículas na graduação. Ademais, verifica-se que $71 \%$ dos cursos presenciais são de bacharelado, enquanto metade (50\%) dos cursos de EaD são de licenciatura ${ }^{11}$.

Um ponto de reflexão neste tema se refere à aparente democratização do acesso ao ensino, quando, na realidade, este projeto se insere na mesma lógica educacional do desenvolvimento desigual e combinado, acrescentando mais um elo ao dilema da relação dialética: qualidade/quantidade.

Já a Pesquisa de Avaliação da Qualidade dos Assentamentos de Reforma Agrária no Brasil - PQRA, realizada pelo Instituto Nacional de Colonização e Reforma Agrária (INCRA) em 2010, no que se refere à educação, aponta os seguintes indicadores:

O Brasil possui 923.609 famílias vivendo em 8.763 assentamentos ${ }^{12}$, numa área de 75,8 milhões de hectares de terra. Deste contingente populacional, 15,58\% não foram alfabetizados; $42,27 \%$ cursaram apenas até a $4^{a}$ série; $27,27 \%$ concluíram 0 ensino fundamental; 7,36\% fizeram uma parte do ensino médio e 6,04\%

\footnotetext{
${ }^{11}$ Ministério da Educação. Censo da Educação superior de 2009: resumo técnico. Brasília, 2010.

12 Assentamentos são áreas agrícolas (territórios) que foram desapropriadas pelo Governo Federal e nelas efetivou-se o assentamento de famílias de trabalhadores Sem Terra através das lutas e passam a ter uma articulação, organização interna e o vínculo com o MST e/ou outros Movimentos que lutam pela terra no Brasil.
} 


\section{perifèria}

Número 16, junio 2012

revistes.uab.cat/periferia - www.periferia.name

concluíram a Educação Básica (nível fundamental e médio). Ou seja, o índice de analfabetismo nos assentamentos é muito superior à média nacional e, se somados com os analfabetos funcionais, chega-se aproximadamente a $60 \%$ o total de pessoas nesta condição, o que mantém a lógica histórica de exclusão dos camponeses à escolarização formal.

Os piores indicadores estão nas regiões Nordeste e Centro-Oeste, seguidas da região Norte. No Nordeste, o índice de não alfabetizados é de $18,41 \%$; no CentroOeste, de 13,86\% e, no Norte é de 11,06\%. Em todas as regiões do país, metade da população brasileira tem, em média, apenas quatro anos de escolaridade e apenas um quarto da população conclui o ensino fundamental.

Trata-se, portanto, de uma realidade criada pela negação do direito à educação e à escola às populações do campo. Este é um fenômeno histórico que se apresenta, no Brasil de hoje, como fruto de múltiplas determinações do poder centralizado pela classe dominante, apesar das propaladas políticas de expansão e universalização do ensino.

Sobre a educação no campo, tomados como referência os dados do Censo Escolar, INEP/MEC, observa-se que existiam no meio rural, em 2002, 107.432 escolas. Em 2009, o número de escolas no campo caiu para 83.036. O que significa o fechamento de 24.396 estabelecimentos de ensino nas áreas rurais. Destes estabelecimentos, 22.179 são de escolas municipais. Esses dados representaram uma redução de mais de $39 \%$ do total de estabelecimentos de ensino no meio rural nas regiões Sul e Centro-Oeste; de 22,5\%, na região Nordeste; de $20 \%$ na região Sudeste e de $14,4 \%$ na região Norte.

Somente na região Nordeste foram fechadas mais de 14 mil escolas, o que significa que mais da metade do total de estabelecimentos fechados! Observa-se, portanto, a íntima relação existente entre os índices de analfabetismo e a dificuldade de acesso à escola, exatamente ao inverso daquilo que proclamam as políticas públicas: o de terem ampliado os recursos públicos que permitem o acesso e permanência das crianças e adolescentes na Escola! 


\section{perifèria}

Número 16, junio 2012

revistes.uab.cat/periferia - www.periferia.name

Com essa política, o número de matrículas no meio rural, nos referidos anos, foi reduzido de 7.916.365 para 6.680.375 educandos, isto é, praticamente 1.235.990 de crianças ficaram sem escola ou foram obrigadas a estudar na cidade. É preciso constatar que, embora haja a nucleação intra-campo, a qual, quando discutida com as comunidades, pode ser uma alternativa, a maioria das escolas foi fechada de forma arbitrária, sem levar em consideração as discussões com os Movimentos Sociais e comunidade rural em geral, promovendo uma política arbitrária relativa à legislação que garante o acesso universal à educação básica.

É mister observar, portanto, a íntima relação existente entre os indicadores até aqui mencionados, no que tange ao índice de analfabetismo no campo e nos assentamentos, e a política de fechamento de escolas no campo. Mais uma vez, como parte explorada do processo histórico de desenvolvimento desigual e combinado, os camponeses continuam impedidos de ingressar, freqüentar e permanecer inseridos nos processos formais de escolarização, o que mantém os altos índices de analfabetismo formal e funcional no meio rural.

Em função desta problemática tornada invisível ao conjunto da sociedade, dada a supremacia quantitativa da cidade sobre o campo, tanto na política pública, como no modo como os meios convencionais de projeção ideológica, como a mídia televisiva e impressa, ocultam o tema, em 2010, o Movimento dos Trabalhadores Rurais Sem Terra (MST) decidiu desencadear uma campanha contra o fechamento das escolas do campo, com o lema: "Fechar escola é crime!"

A campanha visa abrir um debate político com os governos locais e convocar setores da sociedade civil para se somarem à luta histórica pelo direito à educação pública, de qualidade, sem necessidade das crianças, dos jovens e dos adultos migrarem para as cidades como única alternativa que a sociedade Ihes oferece para que possam continuar a estudar.

Daí a necessidade e importância das camadas populares compreenderem essa realidade e a partir das experiências e ações coletivas, buscarem alternativas de pressão junto ao Estado para alterar esse quadro, que mantém a exclusão e os baixos índices de escolaridade. Dessa maneira, não se trata apenas de lutar pela 


\section{perifèria}

Número 16, junio 2012

revistes.uab.cat/periferia - www.periferia.name

garantia de acesso e permanência na escola, precisamos lutar por uma educação de qualidade. Mas, como se define a qualidade?

\section{A qualidade na educação: elementos para reflexão}

Os números e percentuais apresentados anteriormente, não são frios, nem incolores, muito menos neutros. São a expressão de uma realidade econômica, política e social que possui temperatura, cores e posição política. É evidente que, como resultado do processo histórico de construção do nosso país, essa condição histórica não pode ser superada em curto espaço de tempo. Mas já não é mais possível que parte da sociedade permaneça tão indiferente, inerte ou neutra diante deste contexto no qual se reproduz o texto da vida de parte tão expressiva da nossa classe trabalhadora.

Basta uma dose de sensibilidade social e compromisso político-educacional para argumentar em favor da mudança e da construção de uma educação de qualidade, não como mera retórica, e sim, como opção da práxis - teoria da ação reflexiva e propositiva - de vida e de cultura, em síntese, como opção da luta de classes.

Deve-se partir da própria questão aberta pelo item: O que significa falar e adotar o termo qualidade na educação? Que implicações vêm à tona quando se decide lutar pela construção de uma educação de qualidade? Evidentemente, essas questões terão mais do que uma resposta, dada a disputa política travada pelas classes em seus distintos interesses de conformação do poder, como por exemplo, a perspectiva neoliberal e a perspectiva progressista no campo educacional. No fundo, a resposta depende de valores que cada grupo defende, da visão de mundo assumida, do tipo de sociedade projetado. Depende da posição social e política dos envolvidos nos processos; portanto, coloca em evidência que a neutralidade é um discurso operativo do poder de mando de uma classe que, ao dominar, pretende manter-se permanentemente no topo da hierarquia institucional.

Esse tema da qualidade está fundado nas raízes históricas do Brasil, mas sua atualidade se recoloca devido às distintas interpretações e significados que o termo pode adquirir e, em função do jogo de interesses manifesto e oculto por este debate. Ou seja, a qualidade pode falsear realidades a partir de discursos e 


\section{perifèria \\ Número 16, junio 2012 \\ revistes.uab.cat/periferia - www.periferia.name}

perspectivas que atendem critérios e demandas políticas, como também, pode e deve ser apropriada pelos que acreditam e lutam por uma educação crítica de qualidade.

É neste terreno movediço que se apresenta a dialética quantidade - qualidade que requer ser superada enquanto movimento contrário ao do ocultamento-alienação e desvelamento-libertação, permitindo que quantidade e qualidade no Brasil sejam fundidas numa mesma dimensão de inclusão e emancipação.

Para Araujo e Oliveira (2004:7):

... o conceito de qualidade vem sendo bastante utilizado no processo produtivo. Temos discursos que evocam a qualidade total e a necessidade de melhoria na qualidade para aumentar a competitividade do produto brasileiro.

Nessa acepção, o termo qualidade pode adquirir, segundo esses autores, dois sentidos: o primeiro está relacionado à qualidade do produto, sem preocupação com os custos, busca organizar o processo produtivo para a eficiência no resultado de um produto de qualidade; o segundo está relacionado à qualidade do processo, onde se busca produzir um objeto com o menor custo possível para colocar no mercado de forma barata e/ou de baixa qualidade a mercadoria com menor valor de troca, ou seja, os educandos da classe trabalhadora imersa nas margens excludentes do desenvolvimento desigual e combinado.

Essa distinção é significativa, pois,

o conceito de qualidade, mesmo no mundo dos negócios, carrega significados

e procedimentos distintos. Também não se deve perder de vista que parte significativa do debate sobre qualidade na educação é importada do mundo dos negócios, e, ainda assim, nesse âmbito restrito, embute sentidos distintos (Araujo e Oliveira, 2004:7).

Desde um ponto de vista histórico, segundo os autores acima mencionados, no Brasil, pode-se distinguir três significados distintos de qualidade: 


\section{perifèria}

Número 16, junio 2012

revistes.uab.cat/periferia - www.periferia.name

Um primeiro, condicionado pela oferta limitada de oportunidades de escolarização; um segundo, relacionado à idéia de fluxo, definido como número de alunos que progridem ou não dentro de um determinado sistema de ensino; e, finalmente, a idéia de qualidade associada à aferição de desempenho mediante testes em larga escala (Araujo e Oliveira, 2004:8).

Com essa concepção e significado, o sistema educacional brasileiro, mesmo sem um debate público aprofundado no que tange à melhoria da qualidade da educação, difundiu medidas que acreditavam estar avançando nessa direção: tratar-se-ia de construir e ampliar o número de escolas para expandir o acesso. Contudo, a ampliação do acesso trouxe consigo a questão de que muitos não tinham as mínimas condições para acompanhar as exigências e acabaram encontrando obstáculos no caminho, o que fez com que uma boa parcela da população educacional não permanecesse, nem avançasse na escolarização. Dessa maneira, a qualidade foi compreendida como a quantidade de alunos que avançavam dentro de um determinado sistema de ensino.

No entanto, segundo Araujo e Oliveira (2004:10),

... apesar do aumento expressivo do número de matrículas na etapa obrigatória de escolarização, chegou ao final da década de 1980 com uma taxa expressiva de repetência: de cada 100 crianças que ingressavam na $1^{a}$ série, 48 eram reprovadas e duas evadiam (Brasil, Ministério da Educação, 1998), o que evidenciava a baixa qualidade da educação oferecida à população brasileira.

Para tentar melhorar esses indicadores e buscar uma melhor qualidade, foram implementadas, nos anos noventa, as políticas de "progressão automática", os "ciclos de progressão continuada", que dificultaram a possibilidade de aferir os indicadores de qualidade devido às diversidades regionais e ao próprio sistema de ensino.

Assim, o sistema educacional passa a incorporar um terceiro significado de qualidade, 


\section{perifèria}

Número 16, junio 2012

revistes.uab.cat/periferia - www.periferia.name

... indicada pela capacidade cognitiva dos estudantes, aferida mediante testes padronizados em larga escala, nos moldes do Sistema Nacional de Avaliação da /Educação Básica (SAEB), do Exame Nacional do Ensino Médio (ENEM) e do Exame Nacional de Cursos, conhecido como o Provão, para o Ensino Superior (Araujo e Oliveira, 2004:12).

No entanto, esses indicadores enfrentam dificuldades para aferir a qualidade haja vista a brutal desigualdade entre as regiões do país (como demonstrado anteriormente) e, mesmo dentro do próprio sistema de ensino.

A professora Chaú (2000), critica o sentido de qualidade no âmbito da universidade, definida como competência e excelência, cujo critério é o atendimento às necessidades de modernização da economia e desenvolvimento social, cuja produtividade é orientada a responder: quanto ela produz? Em quanto tempo produz? Com que custo produz? A autora destaca, entretanto, que muitas questões não são indagadas, ocultando a disputa subjacente ao produtivismo, quando em realidade:

o que se produz, como se produz, para que ou para quem se produz, ... opera uma inversão tipicamente ideológica da qualidade em quantidade (Chuí, 2000:217).

Essa é a lógica que predomina nos espaços acadêmicos, uma lógica mercantilista, produtivista, onde a qualidade na perspectiva de Chauí, por vezes, é relegada a um segundo plano.

Na mesma direção, o professor Frigotto (2001:64) expõe:

O campo educativo, da escola básica à pós-graduação, no quadro do ajuste global, é, então, direcionado para uma concepção produtivista e mercantilista, cujo papel é desenvolver habilidades de conhecimento, de valores e atitudes de gestão da qualidade, definidas no mercado de trabalho, objetivando formar em cada indivíduo um bando ou reserva de competências e habilidades técnicas, cognitivas e de gestão que Ihe assegure empregabilidade. 


\section{perifèria}

Número 16, junio 2012

revistes.uab.cat/periferia - www.periferia.name

Ou seja, a nova-velha ordem capitalista readequa a escola e a educação tendo em vista a formação geral e profissional, preparando a mão-de-obra que interessa ao capital, tanto do ponto de vista da produção como do consumo. Assim, ou mantém à margem milhões de crianças, adolescentes e jovens, como mencionado anteriormente, ou os inclui a partir de uma política fragmentada, com baixos recursos e sem a preocupação real com a permanência e a qualidade da aprendizagem proposta.

Disto emana a urgência de se debater a questão da qualidade articulada com a função da escola. Qualidade na educação: para quê e para quem?

Busca-se argumentar aqui que a educação de qualidade é aquela que possibilita a superação do medíocre vínculo dos interesses individualistas, mercadológicos e imediatos. Que favorece o entendimento das relações que os homens estabelecem entre si e com a natureza, propiciando a percepção de que o sujeito humano é autor, construtor do contexto atual, da sua história e do seu futuro.

Que a educação de qualidade requer o desenvolvimento de programas e conteúdos disciplinares, práticas pedagógicas, que contribuam para o aprendizado de uma atitude crítica e interrogativa dos educandos durante todo o processo de formação e, posteriormente, no seu exercício político-profissional.

Educação de qualidade é aquela que possibilita ao sujeito conhecer as características, interesses, angústias e aspirações de um povo do qual é partícipe, percebendo as contradições de classe e as perspectivas de superação, mediante um processo de organização e lutas capazes de provocar a ruptura do modelo atual.

É evidente que, para tanto, são necessárias mudanças consubstanciais no que tange à infraestrutura física da maioria das escolas públicas do país, além do processo de valorização do papel do educador nessa nova função social da educação. As escolas devem estar munidas com equipamentos pedagógicos (bibliotecas, salas de cinema e projeção, videotecas, laboratórios, material didático, dentre outros requisitos) capazes de auxiliar na qualidade do processo de ensinoaprendizagem. O Brasil de ontem, que é também o Brasil de hoje, requer, com a mediação dos avanços técnico-científicos, a reiteração da importância da educação 


\section{perifèria}

Número 16, junio 2012

revistes.uab.cat/periferia - www.periferia.name

presencial na vida dos sujeitos mediados pelo mundo. Precisamos da escola como espaço de encontro, estruturada para forjar o novo e destituir o poder delegado pela mercantilização da vida.

É urgente a valorização, em todos os sentidos e níveis, do trabalho docente, pois, é impossível haver ensino de qualidade sem que sejam satisfeitas dignamente as necessidades das pessoas que nele estudam e trabalham. Precisamos garantir, estimular e apoiar todas as possibilidades permanentes de qualificação e formação dos docentes.

Já está claro, também, que necessitamos aumentar 0 montante para 0 financiamento à educação, à pesquisa, à extensão, enfim, um conjunto de medidas que permitam sair da condição que estamos para avançar na inclusão com qualidade de fato. Dai, a luta pelos $10 \%$ do PIB ter se transformado numa bandeira importante de luta e pressão social, aliada com às demandas estratégicas que colocariam a educação entre as prioridades de fato dos governos. Como sustenta Traspadini (2011:01) em seu texto sobre a apropriação privada das fundações do capital sobre os recursos públicos:

A escola pública brasileira não necessita de amigos, e sim de políticas públicas que consolidem direitos e garantam a prioridade na formação da infância e da juventude. A começar pela primazia do público sobre o privado, do trabalhador público como servidor digno e valorizado, da escola pública como espaço próprio e complementar à vida que se requer para além da que se tem. [...] Há um projeto em disputa. É necessário que compremos a briga, que declaremos nossas diferenças, que instituamos nossas verdades frente à fantasia organizada pelo grande capital.

É importante reiterar que o problema não se resolve somente com o aumento dos recursos públicos, mas sem este aumento não conseguiremos efetivar os passos necessários para sanar o déficit educacional historicamente herdado pelo povo brasileiro. Vontade e decisão política aliadas ao incremento de recursos, e, debate e envolvimento com a sociedade, tornam possível a crença na viabilidade das mudanças. E é preciso começar a luta enfrentando o fato de que os limites 


\section{perifèria}

Número 16, junio 2012

revistes.uab.cat/periferia - www.periferia.name

econômicos dos recursos públicos estão atrelados à natureza política das decisões determinadas pela luta de classes ao longo da história.

Como sustenta Carnoy (2000:346) em seu texto a educação como imperialismo cultural:

La nueva educación debe hacer cambiar estos dos elementos del sistema antiguo. En primer lugar, esa educación tiene interés en un sistema social y econômico diferente. La nueva educación deberá en cambio tener por misión la creación o consolidación de una sociedad no jerárquica, en que la propiedad no tenga derechos sobre la gente y en que lo ideal sería que ninguna persona tuviera el derecho de dominar a otra. No sería una sociedad 'igualitaria' en el sentido de que todos fueron iguales: las personas tendrían trabajos diferentes, pero su trabajo no les daría autoridad sobre la vida de los demás. El trabajo se haría para cada quien, por convenio y entendimientos comunes. Este simple ideal implica cambios profundos en el sistema económico, entre ellos las leyes relativas a la propiedad y los cambios que se estudia.

\section{Á guisa de conclusão}

Após navegar pelo mar revolto e depois de viver a dramaticidade da realidade econômica e educacional do modelo de desenvolvimento desigual e combinado brasileiro, certamente não somos mais os mesmos. É praticamente impossível naturalizar essa realidade conflituosa, contraditória e excludente, pois, um país que não consegue nem alfabetizar todo o seu povo não pode ser entendido como uma grande nação. Assim, para conseguir superar a histórica lógica elitista, exclusivista e privatista da educação brasileira precisamos atacar a problemática educacional em todos os seus níveis.

Pensando bem, em termos de quantidade, os indicadores apontam para as maiores dificuldades: são altos índices de exclusão, de analfabetismo puro e simples e, essa quantidade, do ponto de vista dialético, pouco colabora para o salto de qualidade na educação, exigindo por ele a necessidade de enfrentar enormes desafios.

Nas diversas políticas educacionais dos governos recentes de Luis Inácio Lula da 


\section{perifèria \\ Número 16, junio 2012 \\ revistes.uab.cat/periferia - www.periferia.name}

Silva e de Dilma Rousseff, podemos observar certo esforço para ampliar o ingresso e a permanência nos distintos níveis de ensino; trata-se de uma tentativa para melhorar quantitativamente os indicadores, mas estas iniciativas carecem de maior amplitude e qualidade; por isso, estão aquém da verdadeira demanda. Como alertam, acertadamente, Linhares e Garcia (1996:21):

Já não basta repetir que a educação escolar é um direito de todos. É urgente inventar uma outra escola; é urgentíssimo recusarmos um arremedo de vida engessada em corrida de obstáculos, cada vez mais penosos pela garantia de uma sobrevivência indigna da nossa estatura humana; é tempo de enfrentarmos os desafios, de recusarmos a amnésia que as formas bastardas de política insistem em nos oferecer, pois se impõe como intransferível a construção de um projeto potente do qual possamos nos ocupar séria, mas também prazerosamente, nessa virada de século em que nos é dado viver.

Na realidade, está posta a urgência de se pensar um projeto societário a partir de uma nova racionalidade centrada no humano e não em sua mercantil exclusão, capaz de acertar as contas com um passado colonial, escravocrata, dependente e desigual.

Urge construir um Projeto de Nação capaz de superar as mazelas dessa história, que viabilize de forma democrática e radical o acesso de todos aos resultados da produção econômica e cultural, em uma mudança que passa, necessariamente pelo acesso à educação escolar de qualidade para todos/as.

O grande desafio do nosso tempo histórico continua a ser superar a fragmentação, das divisões desnecessárias, os protagonismos inconseqüentes, para construirmos uma ampla aliança que envolva organizações do campo e da cidade que, ao compreender o seu papel histórico, assumam teoricamente e na prática essa luta emancipatória, vital e, portanto, política.

Assim, atuar de forma dinâmica, aberta, comprometida, criadora, num contexto sócio-histórico extremamente complexo como o nosso, marcado pelo avanço do desemprego estrutural, é um modo de recusar essa situação e avançar em uma nova perspectiva. Perspectiva esta que deverá depositar muita esperança nas 


\section{perifèria}

Número 16, junio 2012

revistes.uab.cat/periferia - www.periferia.name

potencialidades do ser humano, nos coletivos criados e recriados, nas tarefas que qualificam prática e teoricamente os profissionais da educação e todos os sujeitos envolvidos nos processos sócio-educativos.

Estas teses estão em consonância com o que sustenta Mészáros (2005:77 em seu livro A educação para além do capital, quando reforça que:

As tarefas imediatas e as suas estruturas estratégicas globais não podem ser separadas ou opostas umas às outras. O êxito estratégico é impensável sem a realização das tarefas imediatas. Na verdade, a própria estrutura estratégica é a síntese global de inúmeras tarefas imediatas, sempre renovadas e expandidas, e desafios. Mas a solução destes só é possível se a abordagem do imediato for orientada pela sintetização da estrutura estratégica. Os passos mediadores em direção ao futuro - no sentido da única forma viável de automediação - só podem começar do imediato, mas iluminados pelo espaço que ela pode, legitimamente, ocupar dentro da estratégia global orientada pelo futuro que se vislumbra.

Atacar de forma radical o problema do analfabetismo e elevar o nível de escolarização do povo brasileiro, primando pela qualidade e a necessária quantidade de inclusão, dos historicamente excluídos, são os grandes desafios a serem enfrentados pela nossa geração.

Por isso, a capacidade de imaginar, de sonhar e lutar para realizar os projetos é fundamental. Precisamos manter viva a utopia da emancipação humana, é ela que nos convoca e nos incita a não parar no que já foi feito. Ao contrário, ela nos convence que é preciso avançar no que ainda está por vir como legado para as gerações futuras. Assim, o sonho, como nos adverte Fernandes (1984:111) precisa ser político e realista:

Quanto ao 'sonho', o que se deve dizer é que sem sonhos políticos realistas não existem nem pensamento revolucionário nem ação revolucionária. Os que não 'sonham' estão engajados na defesa passiva da ordem capitalista ou na contra-revolução prolongada. 


\section{perifèria}

Número 16, junio 2012

revistes.uab.cat/periferia - www.periferia.name

E, para que serve a utopia? O Poeta já nos explicou: a utopia está lá no horizonte. Avanço dois passos, ela se afasta dois passos. Caminho dez passos e o horizonte corre dez passos. Por mais que eu caminhe, jamais alcançarei. Para que serve, então, a utopia? Serve para isso: para que eu não deixe de caminhar ${ }^{13}$.

Dessa maneira, a utopia, o sonho e o compromisso histórico com a construção de uma nova racionalidade humana - que também passa pela educação pública, gratuita e de qualidade para todos/as e em todos os níveis - continua extremante atual: ela nos instiga a continuar a marcha para enfrentarmos e superarmos os enormes desafios do nosso tempo histórico.

\section{Referências Bibliográficas}

Araujo, Gilda Cardoso de e Oliveira, Romualdo Portela de (2004). Qualidade do ensino: uma nova dimensão da luta pelo direito à educação. Revista Brasileira de Educação, no 28, pp. 5-24.

Araujo, Luciana (2011). Como democratizar a universidade brasileira. In: Revista Caros Amigos, no 53, pp. 28-29.

Atlas da Exclusão Social: os ricos no Brasil (2004), volume 3, São Paulo: Cortez.

Carnoy, Martin (2000). La educación como imperialismo cultural. México: Siglo XXI.

Castro, Josué (2007). Geografia da fome. Rio de Janeiro: Civilização Brasileira.

Chaui, Marilena (2000). A universidade em ruínas. In: Trindade, Helio (org). Universidade em ruínas: na república dos professores. Petrópolis, RJ: Vozes, pp. 211-222.

Fernandes, Florestan (1984). O que é Revolução. São Paulo: Abril Cultural.

Fernandes, Florestan (1989). O desafio educacional. São Paulo: Cortez.

Fernandes, Florestan (2009 [1973]). Capitalismo dependente e classes sociais na América Latina. São Paulo: Global.

\footnotetext{
${ }^{13}$ A utopia está no horizonte. Poesia de Eduardo Galeano.
} 


\section{perifèria}

Número 16, junio 2012

revistes.uab.cat/periferia - www.periferia.name

Frigotto, Gaudêncio (2001). Reformas educativas e o retrocesso democrático no Brasil nos anos 90. In: LINHARES, Célia (org). Os professores e a reinvenção da escola: Brasil e Espanha. São Paulo: Cortez, cap. 2, pp. 57-80.

INCRA (2004). II Plano Nacional de Reforma Agrária (PNRA). Brasília: Ministério do Desenvolvimento Agrário.

INCRA (2010). Pesquisa de Avaliação da Qualidade dos Assentamentos de Reforma Agrária no Brasil (PQRA). Brasília: Ministério do Desenvolvimento Agrário.

Leher, Roberto (2010). Educação no governo de Lula da Silva: a ruptura que não aconteceu. In: Os anos Lula: contribuições para um balanço crítico 2003 - 2010. Rio de Janeiro: Garamond, pp. 369-412.

Linhares, Célia Frazão e Garcia, Regina Leite (orgs.) (1996). Dilemas de um final de século: o que pensam os intelectuais. São Paulo: Cortez.

Ministério da Educação (2010). Censo da Educação superior de 2009: resumo técnico. Brasília.

Mészáros, István (2005). A educação para além do capital. Rio de Janeiro: boitempo.

Pochmann, Márcio (2007). Brasil o país dos desiguais. Lê Monde Diplomatique. Ano 1 , no 3, outubro, pp. 16-18.

Stédile, João Pedro (2011). Questão Agrária no Brasil. São Paulo: Atual.

Traspadini, Roberta (2011). 10\% do PIB para a educação já!. São Paulo: Jornal Brasil de fato. Disponível em: HTTP://www.brasildefato.com.br/contente/10-do-pibpara-educação-ja, 23/09/2011. 